\title{
PROCESSO CIVILIZADOR E EDUCAÇÃO ESCOLAR: ALGUMAS ARTICULAÇÕES
}

\author{
PROCESO CIVILIZADOR Y EDUCACIÓN DE LA ESCUELA: \\ ALGUNAS ARTICULACIONES
}

\section{CIVILIZING PROCESS AND SCHOOL EDUCATION: SOME RELATIONSHIPS}

\author{
Daniele Hungaro da Silva \\ Marcos Pereira Coelho ${ }^{\text {II }}$ \\ Gilmar Alves Montagnoli ${ }^{\mathrm{III}}$
}

\begin{abstract}
Resumo Embasado nas contribuições de Norbert Elias, este texto é um recorte das discussões exibidas no XV Congresso Internacional "Procesos Civilizatorios: El Legado de Norbert Elias", realizado na Cidade do México, ano de 2014. Nesse sentido, este artigo tem como objetivo refletir acerca do caráter civilizador da escola. Para tanto, é inicialmente apresentada uma compreensão da teoria dos processos civilizadores, discussão que possibilita compreender, entre outros assuntos, que costumes e comportamentos, muitas vezes imperceptíveis em ações automatizadas, resultam de todo um processo formativo. A constatação motivou a análise da instituição escolar, a qual desde muito cedo atua no sentido de construir determinados comportamentos no corpo infantil. O pressuposto é que a organização escolar age de maneira que a subjetividade e a emoção da criança sejam estruturadas de acordo como o adulto estrutura o seu tempo: exigências da vida em sociedade são desde muito cedo formadas no âmbito micro, que é o ambiente escolar, onde o controle das pulsões, aspecto da teoria de Elias, é diariamente praticado, associado a punições, responsabilidades e limites.
\end{abstract}

Palavras-chave: Educação; Processos civilizadores; Práticas escolares.

\footnotetext{
${ }^{1}$ Universidade Estadual de Santa Catarina

${ }^{\text {II } U n i v e r s i d a d e ~ E s t a d u a l ~ d e ~ C a m p i n a s ~}$

III Universidade Estadual do Maringá
} 
Abstract Based on the contributions of Norbert Elias, this text is a cut of the discussions presented at the XV International Congress "Civilizational Processes: The Legacy of Norbert Elias", held in Mexico City, year 2014. In this sense, this article aims to reflect on of the civilizing character of the school. For that, an understanding of the theory of civilizing processes is presented, a discussion that makes it possible to understand, among other things, that customs and behaviors, often imperceptible in automated actions, result from a whole formative process. The finding motivated the analysis of the school institution, which very early acts to build certain behaviors in the infant body. The assumption is that the school organization acts in such a way that the subjectivity and emotion of the child are structured according to how the adult structures his time: requirements of life in society are very early formed in the micro environment, which is the school environment, where the control of the drives, an aspect of Elijah's theory, is daily practiced, associated with punishments, responsibilities and limits.

Keywords: EduCATION; Civilizing Processes; School PRACTICES.

Resumen Embasado en las contribuciones de Norbert Elias, este texto es un recorte de las discusiones presentadas en el XV Congreso Internacional "Procesos Civilizatorios: E1 Legado de Norbert Elias", realizado en la Ciudad de México, año 2014. En ese sentido, ese artículo en cuanto objetivo, refleja acerca del carácter civilizador de la escuela. Para ello, se presenta inicialmente una comprensión de la teoría de los procesos civilizadores, discusión que permite comprender, entre otros asuntos, que costumbres y comportamientos, muchas veces imperceptibles en acciones automatizadas, resultan de todo un proceso formativo. La constatación motivó el análisis de la institución escolar, la cual desde muy temprano actúa en el sentido de construir determinados comportamientos en el cuerpo infantil. El supuesto es que la organización escolar actúa de manera que la subjetividad y la emoción del niño sean estructuradas de acuerdo con el adulto estructura su tiempo: las exigencias de la vida en sociedad son desde muy temprano formadas en el ámbito micro, que es el ambiente escolar, donde el control de las pulsiones, aspecto de la teoría de Elías, es diariamente practicado, asociado a castigos, responsabilidades y límites.

Palabras clave: Educación; Procesos civilizadores; Prácticas escolares.

\section{INTRODUÇÃo}

O aumento do controle das pulsões, processo analisado historicamente pelo sociólogo alemão Norbert Elias (1897-1990), tem permitido variadas possibilidades de abordagem e contribuído em discussões nas mais diferentes áreas do conhecimento. Ao constatar que desde a Idade Média a vida social vem sendo modelada e explicitar os mecanismos pelos quais isso tem ocorrido, suas teorias têm despertado interesses analíticos diversos. É observada a ocorrência de mudanças de longo prazo nas emoções e estruturas de controle das pessoas, ponto de sua análise que possibilita reflexões educacionais.

Em “O Processo Civilizador”, Elias (1993) defende a ideia de que a ação educativa faz parte de um condicionamento em que os homens tornam-se civilizados. De acordo 
com esse autor, não existe atitude natural no homem, e o processo histórico de ensino-aprendizagem colaborou significativamente para o chamado desenvolvimento dos modos de conduta e comportamento, além de que foi o responsável direto pela formação de um modelo de civilização que se espalhou pelo mundo.

Nesse sentido, o conjunto dessas mudanças é fortemente identificado em práticas institucionalizadas de educação que oferecem contorno, ao longo dos últimos séculos, à formação de crianças e jovens nas escolas. É no âmbito dessa tensão que a presente exposição se movimenta.

A análise de Elias (1993) vem para contribuir com os pesquisadores da área da Educação, no sentido de desvelar durante os tempos e durante os últimos séculos as especificidades, assim como, as representações, de um interesse pelo controle e escolarização dos corpos, demonstrado na preconização de normas de higiene, formas de comportamento que ajudaram na pretensão de se construir modelos de homem e mulher adequados ao processo civilizador do mundo moderno. Esse tem sido tema com frequência pesquisado no campo da História da Educação.

Ao expor a organização da sociedade em Estados, o que contribuiu para o que o autor chama de "processo civilizador", Elias (1993) destaca o aumento do grau de autocontrole em suas respectivas formas, constatando a "[...] peculiar modelação da economia das pulsões que conhecemos pelos nomes de 'vergonha' e 'repugnância' ou 'embaraço" (ELIAS, 1993, p. 242).

Suas obras focam questões a respeito de relações de poder, autocontrole e abrandamento das pulsões, enfatizando de que maneira a estrutura social age sobre o indivíduo biológico de diferentes camadas sociais. Não há na obra de Elias considerações acerca da educação escolar, entretanto, empreenderemos o esforço de articular sua teoria a observações, vivências e estudos sobre a educação escolar, especialmente em sua etapa inicial.

É importante considerar que elementos como a família e a escola são a base da constituição da história da criança. Em geral, é na família que a criança tem sua iniciação social, aprende as relações de interdependência e as regras de convívio do grupo a que pertence. Depois, na escola, ocorre o reforço e a legitimação de tais regras e a continuidade do processo de inserção nas relações de convivência do grupo a que pertence. Desse processo, resulta a formação dos grupos sociais e das relações de interdependência que caracterizam a sociedade.

Com base no exposto, o processo de escolarização da criança é aqui explorado em seu caráter modelador e normatizador em relação ao tempo, espaços e sua sistematização. $\mathrm{O}$ caráter civilizador da escola ocasionou a intensificação da concepção de criança como civilizada em um processo intenso e coercitivo de suas pulsões/emoções. Elias fala em segunda natureza, que pode ser entendida como a internalização de normas, condutas e padrões sociais constituídos a partir da relação entre sociogênese e psicogênese. ${ }^{1}$

Esperamos tornar o entendimento dos termos mais claro ao longo do texto, mas desde já é oportuno apresentar uma definição preliminar. A sociogênese se refere às mudanças sociais que vão refletir nas estruturas psicológicas dos indivíduos, influenciando-as e modificando reciprocamente. Já a psicogênese é a transformação ocorrida na estrutura da personalidade do ser individual. São processos interdependentes. 
A fim de refletir acerca do caráter civilizador escolar com base nas contribuições de Elias, será apresentada, inicialmente, uma compreensão sobre o que o autor denomina de teoria dos processos civilizadores, o que será feito com base na obra "O Processo Civilizador", em que discute, entre outros assuntos, os costumes implícitos no psiquismo humano, que por nós são imperceptíveis em ações automatizadas. Trata-se de mudanças de comportamento e aquisição de cultura, situações que expressam ações educativas.

Em um segundo momento, nosso esforço será no sentido de pensar algumas questões escolares, a educação infantil e a criança. De acordo com Elias, tempo e espaço devem ser analisados conjuntamente, logo, a escola, como espaço de convivência da criança, evidencia a regulação maior desse tempo simbólico. O tempo passa a ser medido como conceito temporal, promovendo maior previsibilidade às ações das crianças, facilitando, adequando e orientando as ações de regulação dos adultos em relação a elas. O fato é que a organização escolar atua de maneira que a subjetividade e a emoção da criança sejam estruturadas conforme o adulto estrutura o seu tempo.

\section{A teoria dos Processos CiVILIZAdores de Norbert Elias}

A compreensão da questão do controle dos impulsos e das paixões em Norbert Elias (1993) exige a leitura de sua obra "O Processo Civilizador", a qual se divide em dois volumes, sendo que o primeiro traz como tema central a discussão sobre o que o autor chama de "Uma história dos costumes", e o segundo volume expõe suas ideias acerca da "Formação do estado e civilização". A teoria social proposta por Elias é por ele denominada de "sociologia configuracional". A compreensão é da existência de uma teia de relações de indivíduos interdependentes que se ligam de diversas maneiras, assim, as relações e funções sociais são vistas como um conjunto de relações interdependentes, que unem os indivíduos entre si numa dada formação. Tal formação seria a configuração, que muda de acordo com cada sociedade, em cada época histórica, contexto.

Amparado nessa ideia, Elias aborda o conceito de processo civilizador. Logo no prefácio de "Uma História dos Costumes", o autor afirma que "[...] grande número de estudos contemporâneos sugere convincentemente que a estrutura do comportamento civilizado está estreitamente inter-relacionada com a organização das sociedades ocidentais sob a forma de Estados" (ELIAS, 1994, p. 16). O entendimento evidenciado é do entrelaçamento e interdependência crescente das pessoas.

Ao definir civilização, o autor ressalta que ela deve ser entendida como um processo contínuo, não acabado ou possuidor de uma única causa. Analisa de maneira relacionada as transformações gerais sofridas pelas sociedades e as alterações ocorridas nas estruturas de personalidade dos indivíduos que a compõem. Dessa forma, não é possível pensar os conceitos de indivíduo e de sociedade como categorias separadas.

Convém enfatizar, desde já, o fato de modificações ocorridas nas estruturas das sociedades afetarem a estrutura da personalidade de seus membros, especificamente no que se refere ao controle dos impulsos, o autocontrole. A análise do autor começa explorando 
as relações sociais na sociedade guerreira, passa pela sociedade feudal, pela sociedade de corte absolutista e termina no advento da sociedade burguesa, caminho que não ocorreu de maneira linear. No percurso, são explicitados mecanismos que possibilitaram a existência de tais sociedades.

De acordo com as formas de relações sociais que se configuram e o grau de interdependência das pessoas, o nível de controle das emoções é alterado. Elias (1993) observa que, na medida em que as pessoas são obrigadas a viver pacificamente em sociedade, entra em cena o controle social, que é a observação de uns pelos outros. Pouco a pouco as pessoas passam a vigiar o próprio comportamento.

Podemos considerar que a sociedade de corte absolutista foi o locus social onde mais se desenvolveu o controle dos impulsos pelos indivíduos e de onde herdamos parte significativa dos nossos costumes e padrões de comportamento que chamamos de civilizados, visto que:

\begin{abstract}
Na sociedade aristocrática de corte, pré-nacional, foram modeladas ou, pelo menos, preparadas partes dessas injunções e proibições que ainda hoje se percebem, não obstante as diferenças nacionais, como algo comum ao Ocidente. Foi delas que os povos do Ocidente, a despeito de suas diferenças, receberam parte do selo comum que os constitui como uma civilização específica (ELIAS, 1993).
\end{abstract}

$\mathrm{Na}$ sequência, ao analisar o advento da sociedade burguesa, Elias (1993) aponta a pressão da competição sobre as diversas funções sociais como um dos motivos para o aumento do autocontrole. O entendimento é que o autocontrole passou a fazer parte da personalidade do indivíduo na medida em que a sociedade se diferenciava, fazendo que aumentassem o número de funções sociais e o grau de dependência entre as pessoas.

À medida que mais pessoas sintonizavam sua conduta com a de outras, a teia
de ações teria que se organizar de forma sempre mais rigorosa e precisa, a fim
de que cada ação individual desempenhasse uma função social. O indivíduo
era compelido a regular a conduta de maneira mais diferenciada, uniforme e
estável. [...] O fato seguinte foi característico das mudanças psicológicas ocor-
ridas no curso da civilização: o controle mais complexo e estável da conduta
passou a ser cada vez mais instilado no indivíduo desde seus primeiros anos,
como uma espécie de automatismo, uma autocompulsão à qual ele não poderia
resistir, mesmo que desejasse. A teia de ações tornou-se tão complexa e exten-
sa, o esforço necessário para comportar-se 'corretamente' dentro dela ficou tão
grande que, além do autocontrole consciente do indivíduo, um cego aparelho
automático de autocontrole foi firmemente estabelecido (ELIAS, 1993, p. 196).

As Funções sociais, desde o período do germe da história do ocidente aos dias atuais, tornaram-se cada vez mais diferenciadas. Quanto mais diferenciadas, tanto mais crescia o número de funções. Confirmando isso, o autor aborda a teia de relações sociais e interpessoais do sujeito com a monopolização do Estado na Idade Média, e com as transformações das práticas de feudalismo do século XII, monopolização do Estado (onde se cria a figura do rei), e o gerenciamento e o controle dos indivíduos por meio do sistema monetário. 
Quanto mais diferenciadas, tanto mais crescia o número de funções e, assim, de pessoas as quais o indivíduo constantemente dependia em todas as suas ações. Dessa forma, a teia de ações teria de organizar-se de modo mais rigoroso e preciso, a fim de que cada ação individual desempenhasse uma função social, obrigando o indivíduo a regular a conduta de maneira diferenciada, uniforme estável. Tal fato não exige apenas uma regulação consciente.

A teia de ações tornara-se mais complexa e extensa, exigindo do indivíduo maior esforço para comportar-se "corretamente" dentro dela. A progressiva divisão de funções e o crescimento de cadeias de interdependência, direta ou indiretamente, tornavam-se integrados em cada ação do indivíduo.

As obras de Elias explicam que essa redução de contrastes na sociedade e nos indivíduos, essa mistura peculiar de padrões de conduta que derivam de níveis sociais inicialmente muito diferentes, são altamente característicos da sociedade ocidental, constituindo-se uma das peculiaridades mais importantes do processo civilizador. O fato é que, para Elias (1994, p. 197), a fixação do autocontrole mental enquanto traço de personalidade do ser humano acontece em função de vários elementos, tal como a "monopolização da força física e a crescente estabilidade dos órgãos centrais da sociedade".

Nessa direção:

Só com a formação desse tipo relativamente estável de monopólios é que as sociedades adquirem realmente essas características, em decorrência das quais os indivíduos que as compõem sintonizam-se, desde a infância, com um padrão altamente regulado e diferenciado de autocontrole; só em combinação com tais monopólios é que esse tipo de autolimitação requer um grau mais elevado de automatismo, e se torna, por assim dizer, uma "segunda natureza" (ELIAS, 1993, p. 197).

O teórico considera que o controle pode ser o controle exercido pelo Estado sobre o indivíduo, por meio de suas leis, como pode ser o controle exercido pelos outros indivíduos dentro do convívio social, ou ainda o autocontrole, um código social de conduta gravado tão fortemente no indivíduo a ponto de tornar-se um elemento constituinte dele próprio, agindo normativamente até quando se encontra sozinho.

Embora não tenha cunhado o conceito de superego, ${ }^{2}$ Elias foi influenciado por ele e pelas contribuições de Sigmund Freud (2013) para desenvolver a ideia de autocontrole. Nessa perspectiva, empreendeu uma análise sobre as redes de controle que, desenvolvidas internamente pelos sujeitos, seriam constituidoras do superego e estruturadas pelas transformações sociais, visto que:

2 Freud concebeu o superego como uma instância psíquica responsável por estruturar internamente os valores morais. O mesmo é dividido em duas partes: o ego ideal e a consciência moral. No primeiro caso, ocorre a internalização dos ideais valorizados pela cultura na qual o indivíduo está inserido, já a consciência moral é responsável pela internalização das proibições sociais. Nas palavras de Freud (2013, p. 83), cabe ao superego “(...) vigiar os atos e intenções do eu e de julgar, exercendo uma atividade censória”. 
Juntamente com a crescente divisão do comportamento no que é e não é publicamente permitido, a estrutura da personalidade também se transforma. As proibições apoiadas em sanções sociais reproduzem-se no indivíduo como formas de autocontrole. A pressão para restringir seus impulsos e a vergonha sociogenética que os cerca - estes são transformados tão completamente em hábitos que não podemos resistir a eles mesmo quando estamos sozinhos na esfera privada. Impulsos que prometem e tabus e proibições que negam prazeres, sentimentos socialmente gerados de vergonha e repugnância entram em luta no interior do indivíduo. Este [...] é o estado de coisas que Freud tenta descrever através de conceitos como "superego" e "inconsciente" ou, como se diz não sem razões na fala diária, como "subconsciente" (ELIAS, 1994, p. 189).

Com base no exposto, o autor considera que geralmente o monopólio da violência física não controla o indivíduo por meio de ameaça direta, mas o controle mais importante se dá dentro do próprio indivíduo. Assim, sociedade alguma pode sobreviver sem que seus indivíduos não internalizem esse tipo de controle. A relação é de uma constante correspondência entre "estrutura social e estrutura da personalidade, do ser individual" (ELIAS, 1994, p. 189).

Enfim, não se pode desconsiderar que, embora não planejada e intencional, a ideia de civilização não constitui uma sequência de mudanças desordenadas e desestruturadas. Para o sociólogo alemão, civilizar não resulta de uma ideia central imutável concebida por pessoas isoladas, implantada em sucessivas gerações como finalidade de ação desejada do Estado, mas significa o controle de outras pessoas convertido, em vários aspectos, em autocontrole.

Após o processo de civilização, as atividades humanas instintivas são reguladas e excluídas do palco comunal, investidas de sentimentos de vergonha e autocontrole que gradualmente tornam-se estáveis, firmes, uniformes e generalizados.

Logo, o controle das pulsões possibilita reflexões acerca do papel desempenhado pela instituição escolar, espaço que em muito contribui no sentido de tornar a conduta das crianças mais próxima dos moldes sociais, uma vez que em virtude do "[...] aumento da proibição social de muitos impulsos, pela sua 'repressão' na superfície da vida social e na consciência do indivíduo, necessariamente aumenta a distância entre a estrutura da personalidade e o comportamento de adultos e crianças" (ELIAS, 1994, p. 147). À luz dessa perspectiva, na sequência, o artigo analisa o caráter civilizador presente na educação escolar moderna.

\section{O CARÁTER CIVILIZADOR NA ESCOLA: A FORMAÇÃO DE SEGUNDA NATUREZA}

Até o presente momento foi possível, com base nas formulações de Norbert Elias, compreender que as transformações sociais nos campos político e econômico de cada período da história geral dos homens associam-se às características de transformação psicológica internas aos indivíduos. Suas teorias permitiram ainda compreender que tais transformações consolidam os efeitos simbólicos do que se considera necessário para experiências e aprendizados da vida em grupo, estas que são mutáveis ao longo do tempo. 
O processo de socialização, chamado por Elias (1994) de processo civilizador, acentuou-se no final da Idade Média e foi marcado pela apreensão de normas e padrões de comportamento, etiqueta, polidez, pudor, trato social, controle de emoções. O processo ganhou dimensão ainda maior no contexto de consolidação da sociedade burguesa, nos séculos XVII e XVIII, quando família e escola deveriam desempenhar papéis centrais no processo civilizador da criança.

Foi aí que se engendrou um modelo tradicional de transmissão de padrões de civilidade entre gerações. Nos primeiros anos de vida, uma família patriarcal realizava a inserção da criança no universo de padrões básicos de comportamento e convívio social, ao passo que, nos anos seguintes, uma escola personalizada fazia a inserção inicial, com o aprofundamento dos padrões de comportamento e convivência e a integração num universo de leis, normas e de distinção de postura entre o público e o privado. Ou seja, a família realizava a socialização primária e encaminhava a criança para que a escola conduzisse a socialização secundária.

Às duas socializações, primária e secundária, implicava uma educação com recato à intimidade corporal. Era preciso, então, esconder o que causava vergonha. O enclausuramento da vida íntima familiar, seja por meio do recolhimento ao dormir, seja pela necessidade de banhar-se, transformou as privações dos indivíduos uma das maiores mudanças no comportamento humano a partir do século XVI e com seu auge no século XIX.

Apesar de mudanças terem ocorrido nessa dinâmica a partir da segunda metade do século XX, sendo estabelecido um quadro no qual a divisão de papéis sociais na educação das crianças não ocorre da mesma maneira, não se pode negar o fato de ambas as instituições, escola e família, continuarem desempenhando papéis de grande importância à civilização das crianças.

Conforme mencionado, a escola é responsável pela constituição daquilo que Elias denomina de "segunda natureza", proporcionando ao aluno o autocontrole de suas pulsões. Importante ressaltar que o ser humano, no início de sua vida social, não possui tendência para autorregulação, sua natureza "animal" é a de satisfazer suas necessidades. Logo, não podem prescindir da mobilização de sua disposição natural rumo à autorregulação mediante o aprendizado pessoal dos controles dos afetos e pulsões, no sentido de um modelo de civilização específico da sociedade, a fim de que possa conviver em sociedade.

O que queremos ressaltar é que o desenvolvimento do autocontrole das paixões e emoções e a capacidade de viver na companhia dos outros resultam de aprendizado, assim:

\footnotetext{
A tendência cada vez mais de pessoas de se observarem e aos demais é um dos sinais de que toda a questão do comportamento estava, nessa ocasião, assumindo um novo caráter: as pessoas se moldavam às outras mais deliberadamente do que na Idade Média (ELIAS 1994, p. 86).
}

Além disso, ressaltamos que a infância e a juventude constituem-se como etapas da vida social nas quais as interações civilizadoras ocorrem de maneira mais privilegiada, visto que é durante essa fase em que o indivíduo "[...] se imprime em sua personalidade em formação, tendo sua contrapartida na relação entre suas instâncias controladoras, o superego e o ego, e os impulsos da libido" (ELIAS, 1993, p. 205). 
É esse o espaço onde se realiza a socialização secundária, ocorrendo a ampliação do contato da criança com determinados padrões de comportamento da comunidade e da sociedade em que está inserida. Isso ocorre por meio dos conteúdos, das normas da instituição, dos eventos que nela são realizados e de todas as vivências que acontecem no espaço escolar.

Conforme mencionado, a família, desde os primeiros anos de vida das crianças, the transmite padrões elementares de sobrevivência e convivência, como nas práticas alimentares, higiênicas, cuidados com o próprio corpo, preocupações com a saúde, a vestimenta, a comunicação verbal, noções de regras, disciplina e hierarquia e toda a autorregulação primária de impulsos de desejos e vontades que começam a ser condicionados ao tempo, espaço e disponibilidade para serem atendidos.

O controle sobre o corpo e o uso dele estiveram na ordem do dia do processo civilizador. Acerca da educação das crianças, firmou-se no século XX, especialmente, um controle e um condicionamento mais efetivo no que tange aos pudores do corpo: "prevalecia a atitude mais severa de que a moralidade e o respeito pelos tabus deveriam estar presentes nas crianças desde os primeiros anos" (ELIAS, 1994, p. 163).

Esse movimento, atravessado pela atenção dedicada aos corpos infantis esteve ligado, com certa frequência, às práticas pedagógicas no âmbito da educação escolarizada similar à formação de segunda natureza que Elias aborda. Tal constatação é possível de ser feita, a partir do caso brasileiro, ao longo do último século.

Após a modernidade, no Brasil, pôde ser observada a introdução de princípios científicos nos currículos da educação escolarizada, a instrumentalização de técnicas para a elaboração de práticas didáticas de intervenção nos comportamentos infantis e o esforço de educadores de adequar ao projeto Estado moderno a instituição escolar na direção de um futuro que exigia um árduo esforço ideológico (HERSCHMANN; PEREIRA, 1994).

No decorrer do século XX, foi possível observar a demarcação dos discursos em torno de substituir o que se supunha ser a escola tradicional por uma "nova escola", moderna e renovada, científica e racional, com vistas à edificação de uma cultura genuinamente brasileira nunca promovida antes. ${ }^{3} \mathrm{O}$ pressuposto da racionalidade científica e da "influência que o meio exerce sobre o indivíduo" estava entre as propostas do Apostolado Positivista ${ }^{4}$ para a educação brasileira, fortemente justificado pela busca de uma educação adaptada às exigências do seu tempo.

Ao buscarmos aspectos da obra de Elias para analisar a situação vivenciada pelo Brasil desse período, é possível constatar que intelectuais da época que assumiam uma postura humanista não mais de apenas narrar, mas também de, em sua narração, cravar suas

Sobre isso, ver "Manifesto ao povo e ao governo" de Fernando de Azevedo, 1932.

4 De acordo com Valentim (2010), o Apostolado Positivista no Brasil abrangeu vários políticos, adeptos da filosofia de Augusto Comte, tais como Rui Barbosa, Lourenço Filho e o mais influente deles, Benjamin Constant. Conforme o mesmo autor, a partir da segunda metade do século XIX, o postulado da filosofia positivista permeou os discursos de racionalidade, propagados por uma elite de intelectuais brasileiros. Tais influências estimularam movimentos de caráter republicano e abolicionista, em oposição à monarquia e ao escravismo dominante no Brasil. Dessa maneira, a Proclamação da República, ocorrida em novembro de 1889 por meio de um golpe militar, com o apoio de setores da aristocracia brasileira, foi o resultado "natural" desse movimento. 
observações e sua experiência da vida social, no sentido de apontar caminhos para novas posturas e códigos sociais que, aos poucos, se tornariam regras de civilidade concernentes a todo o corpo social (ELIAS, 1994).

Nesse momento, a reorganização da estrutura econômica ancorada em modelos industriais passou a demandar artefatos de controle e contenção das emoções comuns às redes de convívio social, estreitando as conexões entre as funções da escola e os objetivos do Estado. No esforço pedagógico de construção do homem moderno que o Brasil necessitava, começava a materializar-se a pretensão de edificar um corpo forte e sadio, oferecendo à escola a tarefa da modelação de condutas.

Tal movimento, sustentado nas ciências da Sociologia, Psicologia e Biologia, capazes de interpretar fenômenos sociais e os comportamentais do indivíduo infantil, passou a assumir, cada vez mais, uma função disciplinadora. Os professores eram incumbidos de conhecer essas ferramentas científicas para a compreensão do desenvolvimento psíquico, fisiológico e social a fim de instrumentalizar-se para a análise e o entendimento das especificidades da progressão dos escolares.

Desde os testes de inteligência propostos por Lourenço Filho (1978), até os mais recentes gabinetes biométricos, ambos instalados no país em meados de 1930, fez-se atribuir à pedagogia o caráter científico, novo, moderno e experimental passando pelo alinhamento de corpos e condutas a uma forma padrão de normalidade. As anomalias e degenerescências corporais, por exemplo, precisavam ser identificadas e, quando possível, curadas, passando a ser responsabilidade de um professor bem instruído o combate da proliferação de doenças e anomalias no âmbito escolar.

Tal discurso científico sobre as relações entre aprendizagem e saúde demonstra, como já mensurado, a interferência das ciências Biologia e Psicologia na área da educação e a assunção de uma Pedagogia tomada como ciência de mensuração e, eminentemente, ortopédica e higiênica.

Alguns desses recursos provenientes dos debates em âmbito nacional vinham sendo aplicados no Estado, mas ainda permanecia a necessidade de garantir condições materiais e técnicas para implantar o modelo escolar que, viabilizando a escola de massas, em outros países já estava vigente. Fatores como a seriação do ensino, homogeneização das classes, regulamentação e uniformização do tempo escolar, o enquadramento disciplinar e a organização do espaço escolar, aliados a uma nova estruturação do conceito de atividade, surgem como novos guias às práticas escolares modernas.

Traçados estes aspectos com a finalidade de expor mais sistematicamente o conteúdo de nossas análises, estas normatizações foram pensadas, no contexto, como uma série de objetivos políticos a serem assumidos pela escola e para os quais a formação docente tornou-se um importante instrumento atrelado ao sentido civilizador da escola.

Nesse sentido, o contexto histórico-educacional do Brasil do século XX nos possibilita compreender, a partir da abordagem sociológica de Elias, o quanto a instituição de ensino formal foi decisiva no sentido de formar comportamentos por meio de práticas pedagógicas regulatórias. 
Nessa perspectiva, é possível observar duas vértices das preocupações com o ensino no Brasil durante esse período: a assimilação e ciência, o que possibilitou a emergência de uma pedagogia direcionada aos processos de autorregulação do sujeito.

Destarte, o que se quer chamar atenção ao nos referirmos aos processos civilizadores presentes nos discursos do período republicano no Brasil é para o fato de que houve a necessidade crescente para a sujeição do indivíduo, do domínio de si para o desenvolvimento de um aparato psíquico forte e regulado utilizado pelas práticas pedagógicas para esse fim, instituindo uma estruturação de tempo mais frequente no corpo infantil.

Ainda hoje, é possível observar práticas pedagógicas que, tidas como práticas modernas no interior do cotidiano escolar, estão amparadas na sujeição do indivíduo e nas concepções de controle e autocontrole discutidas no decorrer deste artigo, como a formação de filas, condutas e modos de comportar-se para comer, vestir-se, portar-se, aspectos de educação moral em alguns casos, ligados à formação religiosa, de obediência, disciplina, civismo e de assistencialismo.

\section{CONSIDERAÇões FINAIS}

O artigo buscou analisar a escola como uma instituição que modela comportamentos, disciplina o sujeito e estabelece condutas por meio de alguns procedimentos que estão amparados em ações que o professor incorpora à rotina escolar, e que são, portanto, intencionais e programados.

As leituras das obras de Norbert Elias possibilitaram-nos a ressignificação do conceito de educação, que é o meio e o modo pelo qual, dolorosamente, fomos e somos condicionados a adaptar e frear as pulsões naturais, com vistas a atingir o grau de civilização. $\mathrm{Ou}$ seja, qualquer forma de educação requer autocontrole e ação com parcimônia no tempo determinado pelas normas.

Assim sendo, podemos argumentar que a escola, como locus principal do processo educacional dos sujeitos, é a instituição que compartilha "o padrão social a que o indivíduo fora inicialmente obrigado a se conformar por restrição externa é finalmente reproduzido, mais suavemente ou menos, no seu íntimo através de um autocontrole que opera mesmo contra seus desejos conscientes" (ELIAS, 1994, p. 129). Nesse sentido, a instituição escolar faz parte de um projeto civilizador sustentado pela ciência, técnica e racionalização do trabalho crescente.

Contudo, a ênfase dada a esta análise buscou entender de que maneira os elementos escolares são colaboradores para que a escola se torne um espaço de regulação, homogeneização, disciplinarização, ordenação e higienização de hábitos e comportamentos, assumindo-se assim, como disciplinadora das pulsões do indivíduo por meio da ação educativa.

Dessa maneira, no primeiro item "A teoria dos processos civilizadores de Norbert Elias", o objetivo foi trazer as discussões que Elias faz sobre o que muda no curso do processo que denominamos de história que, de acordo com ele, são as relações mútuas, as configurações pessoais e a modelação que o indivíduo sofre por meio delas. Nesse sentido, 
vimos que tensões e lutas, tanto quanto as dependências mútuas de pessoas, constituíram parte integral da estrutura civilizadora, afetando decisivamente a direção que ela tomou.

Já a ênfase dada aos aspectos da formação de segunda natureza evidenciados no segundo tópico fundamentou metodologicamente esta análise que pretendeu estabelecer conexões com o papel da escola no contexto da sociedade brasileira do século XX. Nesse item identificamos que a escola, como instituição, forma no indivíduo o autocontrole e o espírito de previsão dos resultados de seus atos, posturas essenciais na vida em sociedade. Sendo assim, a sociogênese e a psicogênese são processos que ocorrem de maneira ampliada na sociedade, mas também nos espaços delimitados, como na instituição escolar.

No decorrer do artigo, as discussões em Norbert Elias são direcionadas a compreender que as tensões e paixões que eram liberadas diretamente na relação entre as pessoas passaram a ser controladas pela escola. Assim, conforme destacado, o conjunto de práticas científicas justificado como as instruções de uma "nova escola" foi inserido com o objetivo de civilizar o cidadão moderno.

Enfim, em todos os casos em que encontramos processos civilizadores de qualquer extensão, encontramos similares estruturais no contexto sócio-histórico mais amplo, no qual ocorreram mudanças de mentalidade. No mais, a discussão realizada ao longo deste texto possibilitou, além da compreensão de aspectos básicos das formulações de Norbert Elias acerca dos processos civilizadores, refletir a respeito do papel da escola na inserção de crianças no universo de padrões e normas de comportamento, etiqueta, convivência e sociabilidade. Ressaltamos a educação escolar em suas possibilidades de "civilização", isso porque a instituição facilita a difusão de padrões de conduta, incorporando indivíduos à rede de interdependências sociais, políticas e econômicas.

\section{REFERÊNCIAS}

ARNAUT DE TOLEDO, Cézar de Alencar. Civilidade, pueridade e educação. In: MACHADO, Maria Cristina Gomes; OLIVEIRA, Terezinha (Org.). Educação na história. São Luis: Editora UEMA, 2008, p. 209-228.

AZEVEDO, Fernando. Manifesto ao povo e ao governo (1932). In: A educação entre dois mundos. São Paulo: Melhoramentos, 1957.

BRASIL. Constituição dos Estados Unidos do Brasil, 10 de novembro de 1937. Disponível em: http:/www.planalto.gov.br/ccivil_03/constituicao/constitui\%C3\%A7ao34.htm

ELIAS, Norbert. O Processo Civilizador: Formação do Estado e Civilização. Tradução de Ruy Jungmann. Rio de Janeiro: Jorge Zahar Ed., 1993, 2 v.

ELIAS, Norbert. O Processo Civilizador: Uma História dos Costumes. Tradução de Ruy Jungmann. Rio de Janeiro: Jorge Zahar Ed., 1994, 1v. 
ELIAS, Norbert. A Sociedade de Corte: investigação sobre a sociologia da realeza e da aristocracia de corte. Tradução de Pedro Süssejing. Rio de Janeiro: Jorge Zahar Ed., 2001. FREUD, Sigmund. O Mal Estar na Civilização.Tradução de Paulo César de Souza, 1. ed. São Paulo: Pinguin Classics Companhia das Letras, 2011.

HERSCHMANN, M. M.; PEREIRA, C. A. M. A invenção do Brasil moderno: Medicina, Educação e Engenharia nos anos 20-30. Rio de Janeiro: Rocco, 1994.

LOURENÇO FILHO, M. B. Introdução ao estudo da Escola Nova, 13. ed. São Paulo: Edições Melhoramentos, 1978.

VALENTIM, Oséias Faustino. O Brasil e o Positivismo. Rio de Janeiro: Publit, 2010.

\section{Daniele Hungaro da Silva}

Doutoranda em História e Historiografia da Educação pela Universidade Estadual de Santa Catarina. Mestra em Sociologia e História da Educação pela Universidade Federal de Santa Catarina (2015). Licenciada em pedagogia pela Universidade Estadual de Mariná (2012).

\section{Marcos Pereira Coelho}

Possui graduação em História pela Universidade Estadual de Maringá (2000) e mestrado em Educação pela Universidade Estadual de Maringá (2006). É doutor pelo Programa de Pós-Graduação em Educação da Universidade Estadual de Campinas.

\section{Gilmar Alves Montagnoli}

É formado em Pedagogia pela Universidade Estadual de Maringá (UEM). Mestre e doutor em Educação também pela UEM, é docente, na mesma instituição, do Departamento de Teoria e Prática da Educação (DTP).

Submetido em: 26-7-2017

Aceito em: 5-3-2018 